\title{
Small Medium Enterprises Insurance Credit Risk Management
}

\author{
Dr. Chulaporn Kobjaiklang \\ Rattana Bundit University \\ Dr. Terdsak Rojsurakitti \\ Rattana Bundit University
}

\begin{abstract}
Thai SMEs have played a vital role in the Thailand economy. However, SME has structure of short term financial characteristics as they depend mostly on short term loan. Thus, we have to be aware of financial distress of SMEs. The study has examined empirical evidence from Thailand insurance industries to identify differences between financial profiles of financially distressed SMEs and non-financially distressed SMEs. We have developed and tested a multiple discriminant analysis model to distinguish between financially distressed SMEs and non-financially distressed SMEs using three categories of financial ratios: liquidity, leverage and profitability. The results show that distressed firms SMEs had lower liquidity, higher leverage and lower profitability ratios than non-financially distressed SMEs. Study tested the statistical significance of the differences between financially distressed SMEs and non-financially distressed SMEs. The financial ratios of distressed firms were taken into the analysis to develop the prediction model.
\end{abstract}

Keywords: SMEs, financially distressed SMEs, non-financially distressed SMEs, liquidity, leverage, and profitability

\section{INTRODUCTION}

Small to medium sized enterprises (SMEs) in Thailand are defined as those employing less than 200 employees, having investment capital of less than 100 million baht, and fixed assets of less than 100 million baht. (OSMEP, 2005)

In the competitive business world of today, in which flexibility, speed and adaptability are essential for survival and progress, small and medium sized enterprises (SMEs) play an extremely important role in any country's economic development. This is especially so for the 21 members of the Asia-Pacific Economic Cooperation Thai SMEs have played a vital role in the Thai economy over the three decades since the first National Five Year Plan was instigated in 1960. And as a part of this economic development, SMEs in Thailand have been successful in many ways. Of particular note is the fact that the SME's share of GDP in Thailand has reached 39 percent. If farm income and agricultural processing are also included, the share rises to 50 percent (OSMEP, 2003). During the same period, the SME share of exports of manufactured goods reached 38.2 percent of the total value of Thailand's exports. When employment is taken into consideration, Thai SMEs employ about 69 percent.

However, SME has structure of short term financial characteristics as they depend mostly on short term loan. Thus, we have to be aware of financial distress of SME. Then, we have to look for statistic model that analyze financial ratio in to the judgment of what company could become financial distress. 
SME financial distress prediction models can help business managers as an early warning mechanism and creditors to assess financial risk of SMEs in making credit decisions and inform policymakers by highlighting key priority areas. Against this background, this study develops and tests a model to identify SMEs financial distress.

This study's major premise is that financial ratios in isolation fail to provide sufficient basis for making informed judgment about SME failure.

Accordingly, we develop and test a multiple discriminant analysis model to distinguish between financially distressed and non-financially distressed

SMEs using three categories of financial ratios: liquidity, leverage and profitability. Thus, the following research hypotheses are pursued:

\section{The objectives of this study are to:}

- Identify and confirm the factors which are contributing to business performance or failure.

- Construct an innovative performance management conceptual model for SME(s) in Thailand.

Many studied has conducted in order to see the importance of SME especially insurance industry in the growth of the country following the definition of Thai SMEs, Importance of insurance toward Thai economy and SME, Financial distress definition, the benefit of financial ratio to identify financial distress, statistical models development to predict financial distress.

This study adopts a hybrid definition employed in Thailand to identify SMEs using a combination of criteria. SMEs are categorized into production, service and trading firms. They are classified as medium or small enterprises based on both number of employees and the amount of fixed assets excluding land. (Institute for Small and Medium Enterprises Development, 2006). For example, businesses in the production and service sectors are classified as small enterprises if their assets are not more than Thai Baht (THB) 50 million and employ not more than 50 people. They are classified as medium enterprises if the assets are between THB 50-200 million and employ between 50-200 people.2 Businesses in the wholesale trading sector are classified as small enterprises if their assets are less than THB 50 million and employ no more than 25 people and as a medium enterprise if assets are between THB 50-100 million and employ between 26-50 people.

Many firms allow their customers to delay payment for goods already delivered and by offering trade credit they enable their business partners to cope with liquidity problems. The results of empirical studies show that trade credit is a very important source of short-term external finance. 1 To date, a number of empirical and theoretical studies analyzed the demand for trade credit and the provision of trade credit: With respect to the demand for trade credit findings suggest that bank credit constrained firms are more likely to resort to trade credit (Biais \& Gollier, 1997; Petersen \& Rajan, 1997). Suppliers may be willing to provide trade credit to their customers if they have better information about the business and the credit risk of their customers than banks and if they have less problems to obtain external finance than their customers (Schwartz, 1974). Moreover, firms may provide trade credit in order to price discriminate since lengthening the credit period implies a reduction in the effective price (Chee K. NG, Smith, \& Smith, 1999). Hence, suppliers may be more willing to offer trade credit to the most price elastic segment of the market, e.g. credit rationed firms, or they may price discriminate because they may have long-term interest in the survival of the business partner (Petersen \& Rajan, 1997). 
Importance of insurance to Thai Economy or SMEs has quite tremendous exist. The process of insurance has been evolved to safeguard the interests of people from uncertainty by providing certainty of payment at a given contingency. The insurance principle comes to be more and more used and useful in modern affairs. Not only does it serve the ends of individuals, or of special groups of individuals, it tends to pervade and to transform our modern social order, too. The role and importance of insurance, here, has been discussed in three phases: (i) uses to individual, (ii) uses to a special group of individuals, viz., to business or industry, and (iii) uses to the society.

Then, we come to genesis of Corporate Financial Distress As a rule, the term "financial distress" is used in a negative connotation in order to describe the financial situation of a company confronted with a temporary lack of liquidity and with the difficulties that ensue in fulfilling financial obligations on schedule and to the full extent. (Gordon ,1971), (Davydenko, 2005) Very often, financial distress is determined in terms of failure, default, bankruptcy, or distressed restructuring, dependent on the underlying methodology and the objectives of the overall research. As a consequence, theoretical and empirical models of financial distress exhibit to a certain extent an one-sidedness in the context of the analysis questions. They mainly concentrate on the momentary perspective, when the adverse process has reached its lowest point and the decision about insolvency or distressed restructuring has to be made. (Gilson, 1989) However, picking single negative events for the analysis of financial distress as a whole may be incorrect and produce biases. Distortions may arise because the examination of the deepest point of financial distress, also known as default, ignores the fact that the largest losses and increasing financial inflexibility happen several periods before this event occurs. (Ward and Foster, 1997),

The first step in the evolution of the quantitative firm failure prediction model was taken by (Beaver, 1966), who developed a dichotomous classification test based on a simple t-test in a univariate framework. He used individual financial ratios from 79 failed and non-failed companies that were matched by industry and assets size in 1954 to 1964 and identified a single financial ratio. Beaver's study was then followed by (Altman, 1968), who suggested a Multivariate Discriminant Analysis (MDA). By utilizing 33 bankrupt companies and 33 nonbankrupt companies over the period 1946 - 1964, five variables were selected most relevant in predicting bankruptcy. And, the following researcher has studies into many model afterward.

Statistical models development to predict financial distress has come to play important role for good prediction of financial distress. Models and methodologies Principal component analysis, Cluster analysis, CHAID, The Logistic Model.

In order to identify the "healthy" and "unhealthy" Romanian listed companies for the year 2008 we applied several models and methodologies, such as the principal component analysis, a hierarchical cluster, CHAID decision tree model and the logit model. All models classified the listed companies quite good and provided relevant information of the financial ratios that better predict financial distress. The PCA and cluster analysis indicated the following variables: the Profit Margin, ROA, ROE, Profit per employee, Current Ratio, Debts on Equity and Growth rate on Total Assets, the CHAID decision tree model indicated Profit Margin, ROA and Turnover growth, while the logit model indicated Profit Margin and Debts on Equity.

\section{Research Questions}

1. Are there significant differences in liquidity, leverage and profitability ratios of financially distressed and non-financially distressed Thai SMEs. 
2. Is logit model is the good model for measures of liquidity, profitability, and financial leverage classifies Thai financially distressed

\section{Hypotheses}

The research questions of this study give rise to the following Hypotheses $(\mathrm{H})$ :

H1: There are significant differences in liquidity, leverage and profitability ratios of financially distressed and non-financially distressed Thai SMEs.

H2: A Logit analysis model with measures of liquidity, profitability, and financial leverage classifies Thai financially distressed

SMEs and non-financially distressed SMEs more accurately than a possible classification by chance. The first hypothesis enables us to test differences between individual financial ratios of financially distressed and non-financially distressed SMEs. The second hypothesis relates to developing and testing SME failure prediction model by taking several ratios into account.

\section{Research Methodology}

Descriptive research will be used in this study where the raw data is transformed into the form that gives clear understanding and is easy to interpret data. It helps present data in a meaningful way (Sekaran, 1993). Descriptive research seeks to determine the answer to who, what, when, where and how questions (Zikmund, 2003). The definition of SMEs in Thailand explained in the previous section is used as a basis for the purpose

of identifying the population for sampling. Then, a more operational approach was followed to make the best use of available data in Thailand because information regarding SMEs' number of employees and fixed asset size are not available. Therefore, asset size is used as a criterion to classify the size of businesses in this study. This is done by adopting the recommendation of the European Commission that the annual balance sheet (or total assets) should not exceed EUR 43 million (European Commission, 2003), which is THB 2,000 million, to be classified as a small and medium-sized enterprise. Using this criterion, firms with total assets not exceeding THB 2,000 million at year end were classified as SMEs.

For this research, the sample size is determined by estimating proportion and the procedure to use the sample proportion is to estimate the unknown population proportion. The researcher makes a judgment about confidence level and maximum allowance for random sampling error. Thus, the sample size for this research is calculated from the following formula (Zidmund, 2003)

$$
\begin{gathered}
n=Z^{2} p q \\
E^{2}
\end{gathered}
$$

Or

$$
n=Z^{2} p(1-p)
$$

Where, $\mathrm{n}=$ number of items in sample

$\mathrm{Z}^{2}=$ square of the confidence level in standard error units

$\mathrm{P}=$ estimated proportion of success

$\mathrm{Q}=1-\mathrm{p}$, or estimated proportion of failures

$\mathrm{E}^{2}=$ square of the maximum allowance of error between the true proportion and the sample proportion. The allowable error is 0.05 or $5 \%$

Therefore, the total of the sample size to be researched is 


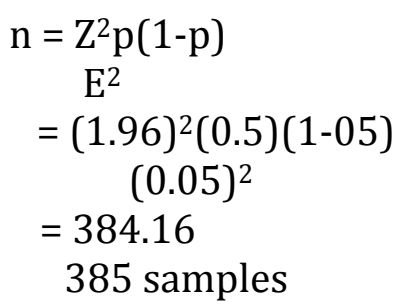

The result of the calculation for the sample size is equal to 385 . However, for the data to be more reliable and accurate, 400 respondents were taken as the sample size.

We gather data from the online information in which the Department of Business Development (DBD). These statements were obtained from the website of the DBD (http://www.dbd.go.th), the former Ministry of commerce, Thailand (Department of Business Development, 2008).

Secondary sources are journals, internet, newspaper, and magazine articles, textbook and previous studies. The purpose of going thoroughly with secondary material also was to find support and guidance for the research that has been undertaken.

\section{STATISTICAL TREATMENT OF DATA}

In this study, we use financial ratio to calculate logit model to determine the financial distress of the company. The logistic model is a conditional probability model that uses maximum likelihood estimation to provide the conditional probability of a firm belonging to a certain group given the values of the independent variables for that firm. It is a single-period classification model (Shumway, 2001) described by the function:

$$
P\left(y_{1}=1\right]=\frac{1}{1+e^{-x_{i} F}}
$$

An important issue in using binary state prediction models such as logit analysis is the selection of the cutoff probability which determines the classification accuracy. In order to classify an observation into one of the two groups, the estimated probability from the logit model is compared to a pre-determined cutoff probability. If the estimated probability is below the cutoff, the observation is classified as an inferior performer and if the estimated probability is above the cutoff, it is placed in the superior performer group.

A total of 385 financial statements of SMEs were used comprising those of 37 financially distressed and 353 non-financially distressed enterprises. The list of the distressed firms was obtained from the website of the Legal Execution Department, Ministry of Justice, Thailand (http://www.led.go.th), (Legal Execution Department, 2008). Thai SMEs that applied to the Thai Bankruptcy Court, the Central Bankruptcy Court and the Civil Court during the period 2002-2005 was used in selecting financially distressed enterprises with assets below BHT 2,000 million. SMEs in the sample may or may not have ceased operations following the bankruptcy because the future of these firms would depend on factors such as the progress of their loan restructuring and plans for improving their performance. Sixty-eight sets of financial statements, i.e., balance sheets and income statements, of financially distressed SMEs were complete and usable.

After identifying SMEs using the criteria explained earlier, 198 financial statements of nondistressed SMEs were considered complete and usable for the study. To avoid a possible sampling bias and to be consistent with the approach we used for selecting financially 
distressed (FD) SMEs, after developing the model, a new sample with three different sets was used to test the model's reliability.

\section{VARIABLE DEFINITION}

The nine independent variables, most commonly used by previous studies, were used in this study classified into liquidity, leverage, and profitability. These ratios are outlined below:

1. Liquidity refers to how quickly and cheaply an asset can be converted into cash, i.e., the ability of current assets to meet current liabilities when due.

2. Leverage, also known as gearing, refers to the use of debt to supplement investment, or the degree to which a business is utilizing borrowed money.

3. Profitability refers to the ability of a firm to generate net income. In the three categories, ratios that are applicable to all selected companies in the sample were chosen.

\section{RESULTS}

Hypothesis 1: Test of differences in financial ratios Comparison of descriptive statistics of financial ratios of FD SMEs and NFD SMEs for the years 2002 to 2005 are presented in Table 1. The variables of interest are the ratios that relate to current liabilities, long-term debts, and profitability. Comparison of mean financial ratios for the two groups of SMEs shows that FD SMEs have lower liquidity, higher leverage and lower profitability than NFD SMEs. This is consistent with the theoretical expectation that non-financially distressed companies exhibit higher liquidity, greater profitability, and lower levels of debt. The distressed firms had a great deal of liabilities which were greater than their assets. Table 1 shows total liability to total assets (TLTA) and long-term liability to total assets (LLTA) ratios were over 100\% for financially distressed SMEs, which resulted in distressed firms having negative equity

(i.e., DE ratio greater than 1). In ideal circumstances liabilities would be kept under total assets, and equity exceeds debt. The study tested the statistical significance of the differences between financially distressed SMEs and non-financially distressed SMEs. Parametric t-tests were conducted on the nine variables to identify statistical significance of the differences between the financial ratios for the two groups of SMEs in the sample. The tests show results that match our expectations (Table 2) in that the variables exhibit statistically significant differences for both parametric and nonparametric tests at a $0.1 \%$ level of significance. The financially distressed SMEs exhibit lowed

Liquidity, higher leverage and lower profitability than non-financially distressed SMEs. Thus, the test of differences shows that there are significant

Differences in liquidity, leverage and profitability ratios of financially distressed and nonfinancially distressed Thai SMEs. 
Table 1: The Financially Distressed (Fd) And Non-Financially Distressed (Nfd) Sme's Insurance Credit Risk Comparative Descriptive Statistics

\begin{tabular}{lcccc}
\hline & \multicolumn{2}{c}{ FD-SMEs } & \multicolumn{2}{c}{ NFD-SMEs } \\
\cline { 2 - 5 } \multicolumn{1}{c}{ Variable } & Mean & SD. & Mean & SD. \\
\hline Liquidity & & & & \\
1) CATA & 40.864 & 25.291 & 71.597 & 20.892 \\
2) CLTA & 172.208 & 44.510 & 41.381 & 23.553 \\
3) WCTA & -107.412 & 75.491 & 40.271 & 20.674 \\
Leverage & & & & \\
4) LLTA & 107.451 & 82.658 & 19.240 & 16.657 \\
5) TLTA & 297.550 & 92.517 & 46.648 & 29.650 \\
6) DE & 278.846 & 152.295 & 38.614 & 28.684 \\
Profitability & & & & \\
7) TITA & 57.326 & 85.031 & 155.594 & 18.461 \\
8) EBITTA & -15.416 & 39.942 & 19.254 & 19.019 \\
9) EAITTA & -19.489 & 58.523 & 12.162 & 15.681 \\
\hline
\end{tabular}

Table 2: Comparative Parametric (T -Test) Results Of Fd-Smes And Nfd-Smes Insurance Credit Risk

\begin{tabular}{|c|c|c|c|}
\hline & \multicolumn{3}{|c|}{ Parametric t-test } \\
\hline & t value & Sig. (1-tailed) & Result \\
\hline \multicolumn{4}{|c|}{ Liquidity of FD-SMEs is less than that of NFD-SMEs } \\
\hline 1) CATA of FD-SME $<$ that of NFD-SMEs & -7.591 & 0.000 & $* *$ \\
\hline 2) CLTA of FD-SMEs $>$ that of NFD-SMEs & 5.218 & 0.000 & $* *$ \\
\hline 3) WCTA of FD-SMEs $<$ that of NFD-SMEs & -6.090 & 0.000 & $* *$ \\
\hline \multicolumn{4}{|c|}{ Leverage of FD-SMEs is greater than that of NFD-SMEs } \\
\hline 4) LLTA of FD-SMEs > that of NFD-SMEs & 7.890 & 0.000 & ** \\
\hline 5) TLTA of FD-SMEs $>$ that of NFD-SMEs & 8.506 & 0.000 & ** \\
\hline 6) DE of FD-SMEs $<$ that of NFD-SMEs & -4.704 & 0.000 & ** \\
\hline \multicolumn{4}{|c|}{ Profitability of FD-SMEs is less than that of NFD-SMEs } \\
\hline 7) TI of FD-SMEs $<$ that of NFD-SMEs & -10.107 & 0.000 & $* *$ \\
\hline 8) EBIT of FD-SMEs $<$ that of NFD-SMEs & -6.298 & 0.000 & $* *$ \\
\hline 9) EAIT of FD-SMEs $<$ that of NFD-SMEs & -5.672 & 0.000 & $* *$ \\
\hline
\end{tabular}

\section{Remark: Sig. (2-tailed) divided by $2{ }^{*}$ Significant at 0.05 level; ** Significant at 0.01 level}

Hypothesis 2: SME failure prediction model development and test have established that the differences in financial profiles between the two groups of SMEs are statistically significant, a distress prediction model for Thai SMEs was developed and its accuracy assessed. A multiple logit analysis model was developed for Thai SMEs in the sample with a view to classifying the firms into financially distressed and non-financially distressed categories. Two approaches are used in selecting variables for the model: 1) using all variables; and 2) selecting variables based on correlation results. Using the first approach, i.e., incorporating all the nine variables into the model, long-term liability to total assets (LLTA) and Working capital to total assets (WCTA) ratios did not pass the tolerance criteria (i.e., the minimum tolerance level of 0.001 , see Hair et al. (1998)). This indicates that some variables are

Likely to exhibit non-normal distributions and also multicollinearity. Therefore, the second approach is employed to closely examine correlation.

Results and select variables for the model with a view to excluding some of the highly intercorrelated variables (Table 3). 
Table 3: Correlations Matrix

\begin{tabular}{|c|c|c|c|c|c|c|c|c|c|}
\hline Variables & CATA & CLTA & WCTA & LLTA & TLTA & $\mathrm{DE}$ & TITA & EBITTA & EAITTA \\
\hline CATA & 1.000 & & & & & & & & \\
\hline CLTA & -0.151 & 1.000 & & & & & & & \\
\hline WCTA & $0.581 * *$ & $-0.611 * *$ & 1.000 & & & & & & \\
\hline LLTA & -0.157 & $0.438^{* *}$ & $\begin{array}{c}- \\
0.495^{* *}\end{array}$ & 1.000 & & & & & \\
\hline TLTA & $-0.319 * *$ & $0.567 * *$ & $\begin{array}{c}- \\
0.598^{* *}\end{array}$ & $0.610 * *$ & 1.000 & & & & \\
\hline $\mathrm{DE}$ & $0.241 * *$ & -0.190 & $0.315^{* *}$ & $-0.303 * *-$ & $-0.298 * *$ & 1.000 & & & \\
\hline TITA & $0.426^{*}$ & -0.181 & $0.245^{*}$ & $-0.317 * *$ & $-0.287^{*}$ & $0.207 *$ & 1.000 & & \\
\hline EBITTA & $0.226^{*}$ & $-0.359 * *$ & $0.601 *$ & $-0.315^{*}$ & $-0.352 *$ & 0.213 & $0.265^{* *}$ & 1.000 & \\
\hline EAITTA & $0.351 *$ & $-0.407 * *$ & $0.443 * *$ & $-0.381 *$ & $-0.612 * *$ & $0.249 *$ & $0.345^{* *}$ & $0.512 * *$ & 1.000 \\
\hline
\end{tabular}

* Correlation is significant at the 0.05 level (2-tailed)

** Correlation is significant at the 0.01 level (2-tailed)

Table 4: Stepwise Logistic Regression: Analysis Of Maximum Likelihood Estimates

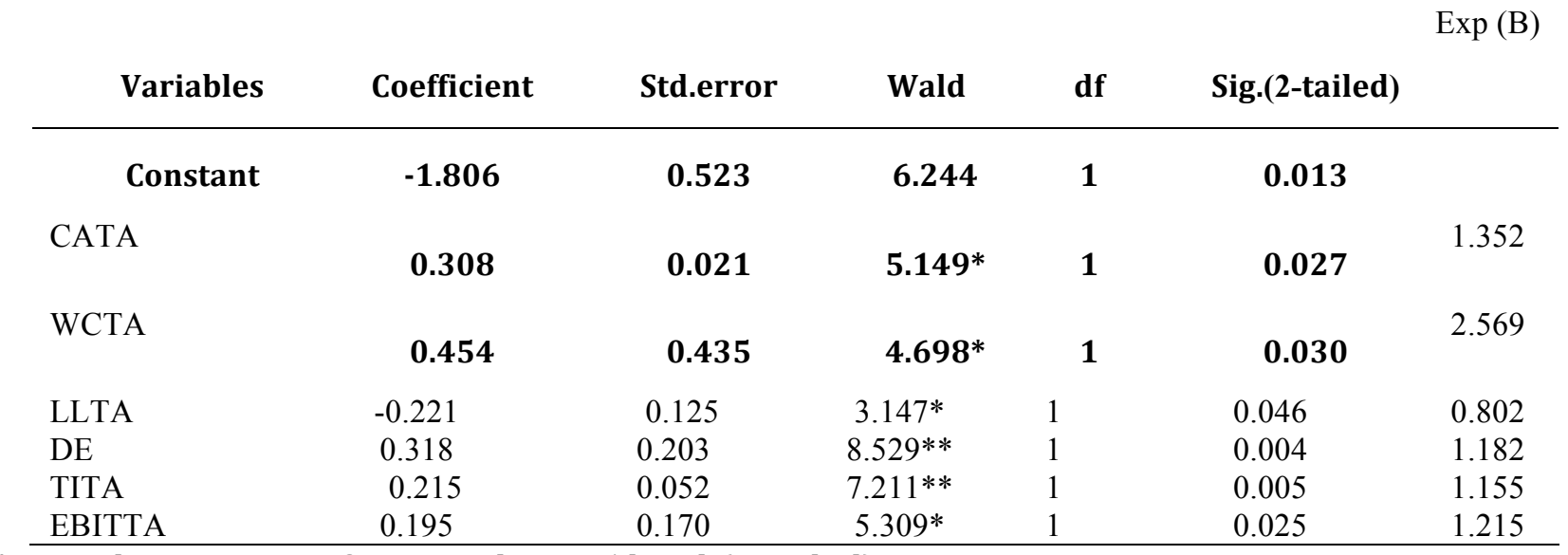

* Correlation is significant at the 0.05 level (2-tailed)

** Correlation is significant at the 0.01 level (2-tailed)

From Table 4, Founded that Logit Regression Model has sixth independent variable: Current assets to total assets ratio (CATA), Working capital to total assets ratio (WCTA), Long-term liability to total assets ratio (LLTA), Debt to equity ratio (DE), Total income to total assets ratio (TITA) and Earnings after interest and tax expenses to total assets ratio (EAITTA). Fourth variables confident level 95\% (Use * symbol) which are CATA WCTA LLTA EBITTA. While another two variables (DE TITA) has $95 \%$ confident level (Use ** symbol). In the same time, CATA WCTA DE TITA EBITTA has positive coefficient. Exp $(B)=1.352,2.569,1.182,1.155$, 1.215 respectively.

If $\operatorname{Exp}(B)>1$ mean independent variable will stimulate the possibility of non-financially distressed. It can show that if CATA WCTA DE TITA or EBITTA has increased $1 \%$, it can stimulate the possibility of non-financially distressed equal to 1.352, 2.569, 1.182, 1.155, 1.215 times respectively. Only one variables which is LLTA that has negative coefficient. Furthermore, $\operatorname{Exp}(B)=0.802(\operatorname{Exp}(B)<1)$ mean that this independent variables will stimulate the possibility of non-financially distressed. If LLTA has increased $1 \%$, it will decrease the possibility of being non-financially distressed 0.802 time.

The result of regression has found that Chi-square statistics has equal to 20.399 which has significant level of 0.01. It mean that independent variables in model has appropriate or it has 
some independent variable has important effect to financially distressed or non-financially distressed of Thai SMEs. Insurance (TABLE 5 (a))

TABLE 5(b) has discovered that 2 Log likelihood statistics has equal to 223.257 which is lower than 2 Log likelihood that has only fixed variable (243.65652). It mean that this logit regression model has result in the same way as empirical study and can define that $\mathrm{R}^{2}$ can be predicted statistical properly equal to 45.2 ( $\mathrm{R}^{2}$ of Cox\& Snell) and 51 percent for Nagelkerke $\mathrm{R}^{2}$.

TABLE 5 (c) has shown the effectiveness of logit regression which can predict financially distressed of Thai SMEs Insurance correctly 84.08 percent and can predict non-financially distressed of Thai SMEs Insurance correctly 87.93 percent. In overall, this logit regression model can correctly predict 87.27 percent.

It can be illustrated in model to study as;

Logit $(Y)=-1.806+0.308^{*}$ CATA $+0.454^{*}$ WCTA $-0.221 *$ LLTA $+0.318^{* *}$ DE $+0.215^{* *}$ TITA + $0.195^{*}$ EBITTA

TABLE 5: Regression analysis of predictive sixth independents variable for financially distressed and non-financially distressed of Thai SMEs. Insurance

(a) Appropriate independent variable in model (Omnibus tests of model coefficients)

\begin{tabular}{llll} 
Statistic Value & Chi-square & df & Sig (2-tailed) \\
\hline Step & $20.399^{* *}$ & 6 & 0.002 \\
Block & $20.399^{* *}$ & 6 & 0.002 \\
Model & $20.399^{* *}$ & 6 & 0.002 \\
\hline
\end{tabular}

* Correlation is significant at the 0.05 level (2-tailed)

** Correlation is significant at the 0.01 level (2-tailed)

(b) Conformity check of model (Model summary)

\begin{tabular}{|c|c|c|c|c|c|c|}
\hline Step & $\begin{array}{l}-2 \\
\text { likelihood }\end{array}$ & Log & $\begin{array}{l}\text { Cox \& } \\
\text { Square }\end{array}$ & Snell R & $\begin{array}{l}\text { Nagelkerkerke } \\
\text { Square }\end{array}$ & $\mathrm{R}$ \\
\hline 1 & 223.257 & & 0.452 & & 0.510 & \\
\hline
\end{tabular}

- 2 Log likelihood has fixed variable $=243.65652$

(c) Corrective prediction of financially distressed and non-financially distressed

\begin{tabular}{llll} 
& Predicted & & \\
\cline { 2 - 4 } Observed & FD-SMEs & NFD-SMEs & Percent Correct \\
\hline FD-SMEs (0) & 30 & 7 & 81.08 \\
NFD-SMEs (1) & 42 & 306 & 87.93 \\
\hline Overall & & & 87.27 \\
\hline
\end{tabular}

Liquidity ratio (CATA, WCTA), Leverage ratio (LLTA, DE), and Profitability ratio (TITA, EBITTA) can classify Thai financially distressed and non-financially distressed of Thai SMEs insurance. Thai financially distressed SMEs and non-financially distressed SMEs more accurately than a possible classification by chance.

\section{CONCLUSION}

The study has examined empirical evidence from Thailand insurance industries to identify differences between financial profiles of financially distressed and non-financially distressed SMEs. It then developed and tested a logit analysis model for predicting SME financially 
distress. The first hypothesis is supported, which shows that there are statistically significant differences between financial ratios of financially distressed and non-financially distressed SMEs in Thailand. The results also exhibited that financially distressed SMEs tend to exhibit lower liquidity than non-distressed insurance SMEs, which arises from the greater use of short-term liabilities. Financially distressed insurance SMEs exhibit higher leverage than nondistressed insurance SMEs and less profitability because of the higher amount of operating costs and interest expenses involved.

The second hypothesis that the predictable of financial ratios in a logit analysis model enables classifying Thai financially distressed and non-financially distressed SMEs more accurately than a possible classification by occasion is also supported.

\section{DISCUSSION}

This study has empirically examined differences between financial profiles of financially distressed and non-financially distressed SMEs in Thailand. It has then developed and tested a logit analysis model to predict SMEs that are in financial difficulty and thus involve high financial risk. The first hypothesis is supported. The results show that distressed firms had lower liquidity, higher leverage and lower profitability ratios. The financial ratios of distressed firms were taken into the analysis to develop the prediction model. The second hypothesis is also supported. This hypothesis predicts that Thai SMEs failure is amenable to prediction to a statistically significant extent using a logit analysis model. The predictive power of the model has a room for improvement. Non-financial variables such as age of business, level of education of business owners or managers, change of auditors, and other qualitative details of business managers, number of years established may also enable researchers to more effectively detect the signs of a financial distress (Altman et al., 2008). However, the main focus of this study was to enhance the usefulness of accounting information by articulating individual ratios into a model. This is a useful approach as financial information is usually the only publicly available information about small firms (Deegan, 2009; Godfrey et al., 2010). Furthermore, the sample is drawn from various industries, which makes the model still amenable to improvement by focusing on specific industries. Models developed using financial data from some industries may not be highly accurate in predicting distress for firms in other industries as financial characteristics of firms cannot be expected to exhibit similarity across several industries. Developing models for particular sectors could improve the predictive power of the model as business failure tends to vary by type of business. For instance, in the United States, the retail sector was the second largest category of corporate business failure between 1992 and 1997 (Dun and Bradstreet, 1998).

Therefore, it is possible that Thai insurance SME could create risk of debt. This implies that policymakers need to help SME insurance for financial as the way of sustainable development. The study contributes to develop and test a model for SME insurance of Thailand, which can also be applied in other emerging industries.

Furthermore, the study has validated the model using a new sample to test the model's practical significance. This makes the model more practical than validating the model with acquiring samples.

1. Policymakers' ability to identify financial distress also assists the Government agencies to predict and prevent distress by providing assistance to potentially distressed firms and issue policy to help non-distress firm to do their business wisely and will not tend to be distressed firm. 
2. SME owners need to set their business strategies to be not distressed. This study give us the understanding of their characteristics of financial ration that have possibility to be distress that may assist in finding timely solutions to the problems.

3. Business consultants in advising their clients on how to develop viable financial strategies.

From the further study point of view, it should be noted that a wide range of variables including non-financial data such as age of business, level of education of business owners or managers, change of auditors, qualitative details of business managers, and age of business may also enable researchers to more effectively detect the signs of a financial distress.

Finally, the sample can draw into other industries, which makes the model still amenable to improvement by focusing on specific industries. Future research could be done focusing on others industries and consider another non-financial variables into the analysis.

\section{Reference}

Annual Report (2008), Bank of Thailand Acharya, V., Sundaram, R., John, K. (2004): On the Capital Structure Implications of Bankruptcy Codes. Working Paper, London Business School.

Altman, E. (1984): The Success of Business Failure Prediction Models. In: Journal of Banking and Finance, 8, 171198.

Altman, E. (2002): Bankruptcy, Credit Risk, and High Yield Bonds.

Blackwell Publishers, Oxford.

Altman, E I. (1968) "Financial Ratios, Discriminant Analysis and the Prediction of Corporate Bankruptcy", Journal of Finance, 23, pp. 589-609.

Andrade, G., Kaplan, S. (1998): How Costly is Financial (Not Economic) Distress? Evidence from Highly Leveraged Transactions that Became Distressed. In: The Journal of Finance, 53(5), 1443-1493.

Asquith, p., Gertner, R., Sharfstein, and D. (1994): Anatomy of Financial Distress: An Explanation of Junk Bond Issuers. In: The Quarterly Journal of Economics, 109, 625-658.

Beaver, W. (1966) "Financial ratios as predictors of failure", Journal of Accounting Research (Supplement), 4, pp. 71-102.

Biais, B., \& Gollier, C. (1997). Trade credit and credit rationing. Review of Financial Studies, 10, 905-937.

European Commission (2003). Commission recommendation: Definition of Small \& medium sized enterprises. Commission Recommendation 2003/361/EC of 6 May 2003. Retrieved from http:www.eif.org/attachments/gurantees/cip/CIP_SME_definition.pdf

Beaver, W. (1966): Financial Ratios as Predictors of Failure. In: Journal of Accounting Research, 5, 71-111.

Broadie, M., Chernov, M., Sundaresan, S. (2004): Oprimal Debt and Equity Values in the Presence of Chapter 7 and Chapter 11. Working Paper, Columbia Business School.

Brown, D., James, C., Mooradian, R. (1993): The Information Content of Distressed Restructurings Involving Public and Private Debt Claims. In: Journal of Financial Economics, 33, 93-118.

Broxtermann, J. (2003): Vulture Investing. Master Thesis, University of St. Gallen.

Campbell, J. (2000): Asset Pricing at the Millennium. In: The Journal of Finance, 55(4), 1515-1568.

Chee K. NG, C. K., Smith, J. K., \& Smith, R. L. (1999). Evidence on the Determinants of credit terms used in interfirm trade. The Journal of Finance,Vol. 54 No. 3 , 1109-1129.

Davydenko, S. (2005): When Do Firms Default? A Study of the Default Boundary. Working Paper, London Business School. 
Denis, D., and Denis, D. (1995): Causes of Financial Distress Following Leveraged Recapitalizations. In: Journal of Financial Economics, 37, 129-157.

Duffie, G., Wang, K. (2004): Multi-Period Corporate Failure Prediction with Stochastic Covariates. NBER Working Paper.

Fitzpatrick, J. (2004): An Empirical Investigation of the Dynamics of Financial Distress. Dissertation, the State University of New York at Buffalo.

Franks, J., Sanzhar, S. (2003): Evidence on Debt Overhang from Distressed Equity.

Gestel, T., Baesens, B., Suykens, J., Van den Poel, D., Baestaens, D., Willekens, M. (2006): Bayesian Kernel Based Classification for Financial Distress Detection. In: European Journal of Operational Research, 172(3), 979-1003.

Gilbert, L., Menon, K., and Schwartz, K. (1990): Predicting Bankruptcy for Firms in Financial Distress. In: Journal of Business Finance \& Accounting, 17, 161-171.

Gilson, S. (1989): Management Turnover and Financial Distress. In: Journal of Financial Economics, 25, $241-262$.

Ghobadian, A, Gallear, D.N. (1996), Total quality managment in SMEs, Omega, Vol. 24 No.1, pp.83-106 Gordon, M. J. (1971): Towards a Theory of Financial Distress. In: The Journal of Finance, 26(2), 347-356.

Hendel, I. (1996): Competition under Financial Distress. In: The Journal of Industrial Economics, 54(3), 309-324.

Hillegeist, S., Keating, E., Lundstedt, K. (2004): Assessing the Probability of Bankruptcy. In: Review of Accounting Studies, 9, 5-34.

Holmes, S., \& Kent, P. (1991). An empirical analysis of the finanical structure of small and large Australian manufacturing enterprises. Journal of Small Business Management, 1(2), 141-154.

Important of insurance, http://www.preservearticles.com/2012040629929/what-is-the-role-and-importance-ofinsurance.html

Institute for Small and Medium Enterprises Development. (2006). Definition of SMEs (in Thai).

Khader, S.A., \& Gupta, C.P. (Eds.). (2002). Enhancing SME competitiveness in the age of globalization. Tokyo: National Statistical Coordination Board, Asian Productivity Organization.

Kraus, A., \& Litzenberger, R.H. (1973). A statepreference model of optimal financial leverage. Journal of Finance 28(4), 911-922.

Office of Advocacy. (1984). the state of small business: A Report of the President. Washington DC: Small Business Administration.

Ohlson, J. (1980): Financial Ratios and Probabilistic Prediction of Bankruptcy. In: Journal of Accounting Research, 18(1), 109-131.

Opler, T., Titman, S. (1994): Financial Distress and Corporate Performance.

In: The Journal of Finance, 49(3), 1015-1040.

Petersen, M. A., \& Rajan, R. G. (1997). Trade credit: Theory and evidence.

The Review of Financial Studies, Vol. 10 No. 3, 661-691.

Pindado, J., Rodrigues, L. (2004): Parsimonious Models of Financial Insolvency in Small Companies. In: Small Business Economics, 22, 51-66.

Platt, H., Platt, and M. (2002): Predicting Corporate Financial Distress: Reflections on Choice-Based Sample Bias. In: Journal of Economics and Finance, 26(2), 184-199.

Purnanandam, A. (2005): Financial Distress and Corporate Risk Management: Theory \& Evidence. Working Paper, Ross School of Business, University of Michigan.

Shumway, T. (2001) "Forecasting bankruptcy more accurately: A simple Hazard model", Journal of Business, 74 (1), pp. 101-124. 
Schwartz, R. A. (1974). An economic model of trade credit. Journal of Financial and Quantitative Analysis, September, 643-657.

The Farlex Financial Dictionary (Ed.) (2011) the Farlex Financial Dictionary, Accessed at 05 May 2011 at: http://encyclopedia.thefreedictionary. Com/Business+failure\#cite_note- 0 .

The White Paper on Small and Medium Enterprises of Thailand in 2004 and Trends 2005 (2005) Office of Small and Medium Enterprises Promotion (OSMEP), Thailand.

The White Paper on the $2^{\text {nd }}$ SME Promotion Plan (2007-2011), Office of SME Promotion, Thailand.

The White Paper on the Thailand Ninth National Economic and Social Development Plan (2001-2006), Office of National Economic and Social Development

Turetsky, H., McEven, R. (2001): An Empirical investigation of Firm.

Longevity: AMolde of the Ex Ante Predictors of Financial Distress. In: Review of Quantitative Finance and Accounting, 16, 323-343.

Ward, T., Foster, B. (1997): A Note on Selecting a Response Measure for Financial Distress. In: Journal of Business Finance and Accounting, 24(6), 869-879.

Warner, J. (1977): Bankruptcy Costs: Some Evidence. In: The Journal of Finance, 32(2), 337-347.

Weckbach, S. (2004): Corporate Financial Distress: Unternehmensbewertung bei Finanzieller Enge. Dissertation, University of St. Gallen.

Wruck, K. (1990): Financial Distress, Reorganization, and Organizational Efficiency.In: Journal of Financial Economics, 27, 419-444.

Zheng, Q. and J. Yanhui (2007), "Financial Distress Prediction on Decision Tree Models", IEEE

Zmijewski, M. (1984): Methodological Issues Related to the Estimation of Financial Distress Prediction Models. In: Journal of Accounting Research, 22, 59-82. 